\title{
Quantification of role of impedance contrast in site-city-interaction effects on the responses of buildings and basin
}

\author{
Jay Prakash NARAYAN ${ }^{1, *}$, Prerna SINGH ${ }^{2}$, Simran VERMA ${ }^{1}$ \\ ${ }^{1}$ Department of Earthquake Engineering, Indian Institute of Technology, \\ Roorkee, India; e-mail: jp.narayan@eq.iitr.ac.in, vermarocks2610@gmail.com \\ ${ }^{2}$ Department of Civil Engineering, Indian Institute of Technology, \\ Delhi, India; e-mail: chhaya20singh@gmail.com
}

\begin{abstract}
This paper presents the role of impedance contrast (IC) at the base of 2D deep elliptical basin (shape-ratio $>0.25$ ) in the site-city-interaction (SCI) effects on both the $\mathrm{SH}-$ and SV-wave responses of buildings and basin. The obtained SCI effects in the form of reduction of fundamental frequencies of building $\left(F_{02 D}^{S B}\right)$ and basin $\left(F_{02 D}^{B}\right)$, corresponding amplification and splitting of the bandwidth of fundamental mode of vibrations of both the building and basin corroborates with the findings in the past SCI studies. The $F_{02 D}^{B}$ of basin and $F_{02 D}^{S B}$ of building are unaffected by an increase of IC during site-city-interaction, even though, there is an increase of $F_{02 D}^{B}$ of basin with an increase of IC in the absence of city. A drastic increase of SCI effects on the basin response but only minor increase of SCI effects on the building response with an increase of IC is observed for both the polarizations of the S-wave. However, the rate of increase of SCI effects with IC is more in the case of SV-wave responses of buildings and basin. The obtained larger $\%$ reduction of $F_{02 D}^{B}$ and corresponding amplification in the case of $\mathrm{SH}$-wave responses as compared to those in the case of SV-wave responses may be due to the larger height of B16-buildings compared to B12-buildings used in the SV-wave simulations or due to the buildings behaving as a shear beam for the $\mathrm{SH}$-wave or may be due to both.
\end{abstract}

Key words: SCI effects on building and basin responses, impedance contrast, free field motion, double resonance condition and polarization of S-wave

\section{Introduction}

The concept of site-city-interaction (SCI) effects on the responses of building and basin was originated when the scientists were trying to find out the reasons responsible for the observed beating phenomenon along with longer duration of ground motion in the Mexico City during the 1985 Mex-

\footnotetext{
${ }^{*}$ corresponding author: e-mail: jp.narayan@eq.iitr.ac.in
} 
ico earthquake (Chávez-García and Bard, 1994; Wirgin and Bard, 1996; Stewart et al., 1999; Guéguen et al., 2002; Tsogka and Wirgin, 2003; Sahar et al., 2015; Guéguen and Colombi, 2016). The SCI effects on both the building and basin responses are due to the combined effects of kinematic soil-structure interaction and inertial structure-soil interaction on a global scale (Housner, 1954; Jennings, 1970; Wong and Trifunac, 1975; Kanamori et al., 1991; Stewart et al., 1999; Bard et al., 2005; 2008). In most of the past SCI studies, the cities were considered on a sediment layer (1D basin) or in a $2 \mathrm{D}$ shallow basin (shape-ratio $>0.25$ ) under double-resonance condition and results were in the form of reduction of fundamental frequencies of building $\left(F_{02 D}^{S B}\right)$ and basin $\left(F_{02 D}^{B}\right)$, spectral amplification factors $(\mathrm{SAF})$ at $F_{02 D}^{S B}$ and $F_{02 D}^{B}$, as well as splitting of the bandwidth of the fundamental mode of vibrations of buildings and basin (Guéguen and Bard, 2005; Kham et al., 2006; Groby and Wirgin, 2008; Semblat et al., 2008; Sahar and Narayan, 2016; Kumar and Narayan, 2018). The shape-ratio of basin is the ratio of its maximum depth to half-width and double resonance is the matching of frequency of the incoming signal with the fundamental frequency of basin $\left(F_{02 D}^{B}\right)$ and further matching with the fundamental frequency of building on rock $\left(F_{02 D}^{S}\right)$. Some researchers have also studied SCI effects theoretically and have validated the outcomes with numerical and experimental results (Schwan et al., 2016).

The response of 2D-shallow basin is dominated with basin generated surface waves and there is a spatial variation of fundamental frequency of sediment deposit in the basin (Narayan, 2005). On the other hand, the response of $2 \mathrm{D}$-deep basin (shape-ratio $>0.25$ ) is dominated with a $2 \mathrm{D}$ resonance phenomenon and entire basin vibrates with a single fundamental frequency (Bard and Bouchon, 1985; Kumar and Narayan, 2018). There is an increase of fundamental frequency of deep-basin with an increase of impedance contrast (IC) at its base (Zhu et al., 2019). The extensive literature review revealed that in most of the past SCI studies, the SH-wave responses of 2D-shallow basins (Kham et al., 2006; Semblat et al., 2008; Sahar and Narayan, 2016) and 2D-deep basins (Kumar and Narayan, 2018; 2019) are used. There are few studies in which SCI effects are studied using SV-wave responses (Kumar and Narayan, 2018). As far as we know, nobody has studied the role of impedance contrast (IC) in the SCI effects on the responses of buildings and basin. Guéguen et al. (2019) reported that the 
fundamental frequency of the shear-beam buildings can be computed using simple relation $F_{02 D}^{S}=V_{S} / 4 H$ (where ' $H$ ' is the height of building), but not that of bending-beam buildings. In the case of bending-beam model, the reduction of fundamental frequency with increase of height is non-linear in nature due to the reduction of bending-stiffness of the building. Kumar and Narayan (2018) stated that the computed fundamental frequency of $2 \mathrm{D}$ building block model (BBM) using SH- and SV-waves is like that of shear-beam and bending-beam models, respectively. So, there is need of quantification of polarization dependent role of IC at the base of deep-basin in the SCI effects on the responses of buildings and basin.

In order to fulfill the above identified scientific gaps, the SH- and SVwave responses of the buildings of a city situated in a deep elliptical basin and free field motion were simulated under double-resonance condition for different IC at the base of basin. The IC has been increased by increasing the impedance of rock. The dimension and rheological parameters of the basin and building are same in all the considered site-city models for a particular polarization of the S-wave. To quantify the role of IC in the SCI effects on the responses of buildings of the city, the response of a standalone building at the centre of elliptical basin is considered as a reference one. Similarly, the role of IC in the SCI effects on the response of basin is quantified considering the response of basin in the absence of city as a reference one. The SH- and SV-wave responses of the various considered site-city models were simulated using recently developed fourth-order accurate visco-elastic staggered-grid SH- and SV-wave finite-difference (FD) programs by Narayan and Kumar (2013) and Narayan and Kumar (2014), respectively.

\section{Model parameters and salient features of FD programs}

\subsection{Parameters of building block model}

In order to study the role of IC in the SCI effects on the SH- and SVwave responses of buildings and basin under double resonance condition, homogenous cities made-up of 16-storey (B16) and 12-storey (B12) buildings, respectively, were considered. The height of one storey is taken as $3 \mathrm{~m}$ based on the prevailing Indian scenario of construction of buildings (IS 1893-1, 2002). Presently, it is impossible to implement the buildings 
of the city in the numerical grid because of lack of computer memory and computational speed. However, the buildings can be incorporated in the numerical grid using BBM, as shown in Fig. 1, taking into account that the different modes of vibrations, dimensions, damping and weight of the BBM are same as that of the real building (Wirgin and Bard, 1996; Bard at el., 2005; 2008; Sahar at el., 2015; Sahar and Narayan, 2016). Michel and Guéguen (2018) stated that the equivalent S-wave velocity for the buildings fall in a range of $100 \mathrm{~m} / \mathrm{s}$ to $500 \mathrm{~m} / \mathrm{s}$ depending on the design and material used based seismic interferometry. The S-wave of the order of $120 \mathrm{~m} / \mathrm{s}$ is taken for the BBM in the present study (Sahar et al., 2015). The computed fundamental frequency of B16-BBM of height $48 \mathrm{~m}$ for the $\mathrm{SH}$-wave $\left(S H F_{02 D}^{S}\right)$ is $0.625 \mathrm{~Hz}$ (Guéguen et al., 2019). The effective density of the BBM was obtained as $350 \mathrm{~kg} / \mathrm{m}^{3}$ for a particular design and material property, using the weights of all the walls, beams, columns, slabs of building and the live load (Sahar et al., 2015). The damping in the BBM for both the P-wave and $\mathrm{S}$-wave was taken as $5 \%$. Table 1 depicts the rheological parameters for the considered building/BBM, sediment in basin and underlying rock.

Table 1. Rheological parameters for the building block model, sediment of basin and rock.

\begin{tabular}{|c|c|c|c|c|c|c|}
\hline \multirow{2}{*}{ Materials } & \multicolumn{2}{|c|}{ Seismic velocity $(\mathrm{m} / \mathrm{s})$} & \multicolumn{2}{|c|}{ Quality factors } & \multirow{2}{*}{$\begin{array}{c}\text { Poisson's } \\
\text { ratio }(\nu)\end{array}$} & \multirow{2}{*}{$\begin{array}{c}\text { Density ' } \rho \text { ' } \\
\left(\mathrm{kg} / \mathrm{m}^{3}\right)\end{array}$} \\
\hline & S-wave & P-wave & Qs & Qp & & \\
\hline Building & 120.0 & 294.0 & 10 & 10.0 & 0.40 & 350 \\
\hline Basin & 300.0 & 735.3 & 30 & 73.5 & 0.40 & 1800 \\
\hline Rock & 1800.0 & 3117.7 & 180 & 311.0 & 0.25 & 2500 \\
\hline
\end{tabular}

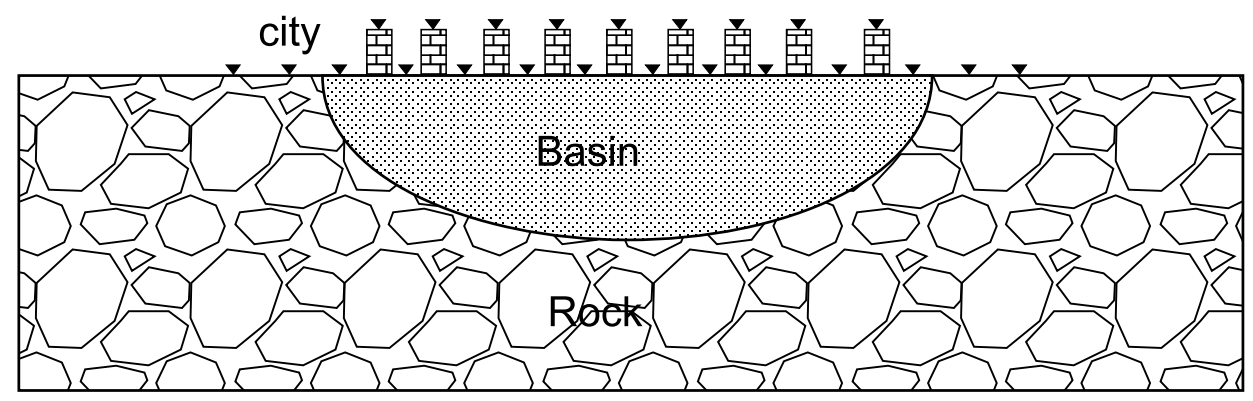

Fig. 1. Vertically exaggerated sketch for the various site-city models (Note: the considered number of buildings are nine and five in the cases of SV- and SH-wave simulations, respectively). 


\subsection{Salient features of FD programs}

A frequency dependent damping in the time-domain simulations of the SHand SV-wave responses of the site-city models is essential for the accurate prediction of SCI effects on the building and basin responses (Emmerich and Korn, 1987; Kristek and Moczo, 2003). A forth-order accurate timedomain SH- and SV-wave viscoelastic finite-difference (FD) programs were used for the simulations (Narayan and Kumar, 2013; 2014). These programs were written for the simulations to be carried out in the XZ-plane of the Cartesian coordinate system. The details of finalizing the input parameters like relaxation frequencies and the computation of anelastic coefficients and unrelaxed moduli are given in Narayan and Kumar (2013; 2014). The centres of basin and city are collocated and are considered as a reference point for all the horizontal distance measurements. An improved vacuum formulation proposed by Zeng et al. (2012) is used as a free surface boundary condition. In order to avoid the edge reflections, sponge-absorbing boundary layers were used at the left, right and bottom edges of the model (Israeli and Orszag 1981; Kumar and Narayan, 2008).

A plane SH- and SV-wave front propagating vertically towards the free surface was generated at a desired depth in the respective FD program using various point sources at every $3 \mathrm{~m}$ distance along a horizontal line from leftedge to right-edge of the model. The envelops of the wave fronts of the individual point source generated a plane wave front propagating towards the free surface. The downward propagating plane wave front was absorbed by the implemented absorbing boundary condition at the bottom edge of the model. The shear stress $\sigma_{y z}$ and $\sigma_{x z}$ in the form of Gabor wavelet was used as a source time function (STF) to implement a point source in the cases of SH- and SV-wave simulations, respectively. The mathematical formulation for the Gabor wavelet is given below:

$S(t)=\exp (-\alpha) \cos \left[\omega_{P}\left(t-t_{S}\right)+\varphi\right]$,

where $\alpha=\left[\frac{\omega_{P}\left(t-t_{S}\right)}{\gamma}\right]^{2}, \omega_{P}$ is predominant frequency, $\gamma$ controls the oscillatory character, $t_{S}$ controls the duration and $\varphi$ is phase shift. The value of parameters $f_{P}=3 \mathrm{~Hz}, \gamma=1.5, t_{S}=0.33 \mathrm{~s}$ and $\varphi=0$ was used. 

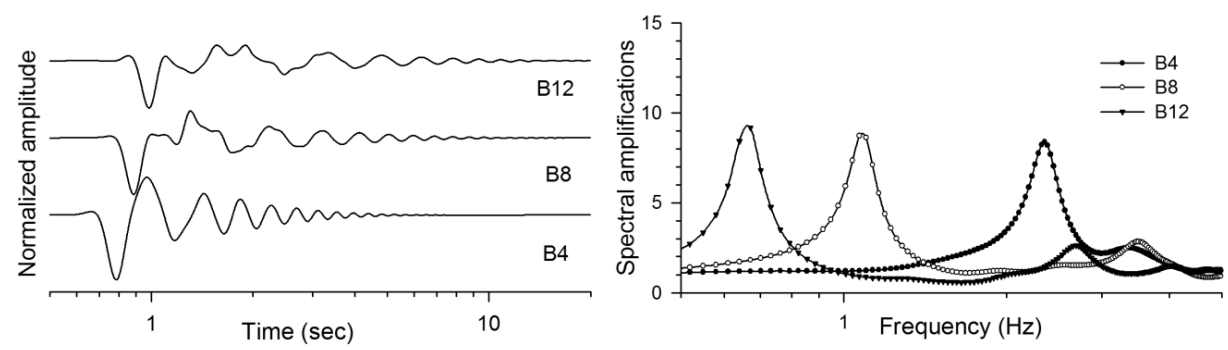

Fig. 2. The horizontal component of SV-wave responses (left) and spectral amplifications (right) at the top of B4, B8 and B12-buildings.

\section{Response of standalone building on rock}

In this subsection, the fundamental frequency of standalone BBM on rock is numerically computed for both the polarizations of S-wave and its variation with IC between the base of BBM and the underlying rock.

\subsection{The $S V F_{\mathrm{O} 2 D}^{S}$ of standalone BBM on rock}

As discussed earlier, the fundamental frequency of BBM on rock for the SVwave $\left(S V F_{02 D}^{S}\right)$ cannot be computed using simple relation $F_{02 D}^{S}=V_{S} / 4 H$ since BBM behaves like a bending beam (Kumar and Narayan, 2018). So, to find out the $S V F_{02 D}^{S}$ of the BBM, the SV-wave responses of the considered standalone B4 (four-storey), B8 (eight-storey) and B12 (twelve-storey) buildings on rock were computed and analysed. The dimensions of B4, B8, B12-buildings are given in the Table 2. The left panel of Fig. 2 depicts the horizontal components of the $\mathrm{SV}$-wave responses at the top of $\mathrm{B} 4, \mathrm{~B} 8$ and B12-buildings. An increase of duration and decrease of amplitude of the $\mathrm{SV}$-wave at the top of building can be inferred with an increase of height of

Table 2. Dimension of considered buildings, $S V F_{02 D}^{S}$ of standalone BBM on rock, $S V F_{02 D}^{S B}$ of standalone BBM in basin and corresponding SAFS.

\begin{tabular}{|c|c|c|c|c|c|c|}
\hline Buildings & $\begin{array}{c}\text { Height } \\
(\mathrm{m})\end{array}$ & $\begin{array}{c}\text { Width } \\
(\mathrm{m})\end{array}$ & $\begin{array}{c}S V F_{02 D}^{S} \\
(\mathrm{~Hz})\end{array}$ & $\begin{array}{c}\text { SAF at } \\
S V F_{02 D}^{S}\end{array}$ & $\begin{array}{c}S V F_{02 D}^{S B} \\
(\mathrm{~Hz})\end{array}$ & $\begin{array}{c}\text { SAF at } \\
S V F_{02 D}^{S B}\end{array}$ \\
\hline B12 & 36 & 60 & 0.66 & 9.18 & 0.64 & 67.27 \\
\hline B8 & 24 & 60 & 1.06 & 8.71 & - & - \\
\hline B4 & 12 & 60 & 2.34 & 8.38 & - & - \\
\hline
\end{tabular}


building. The right panel of Fig. 2 reveals the spectral amplification factors (SAF) for the horizontal component of SV-wave at the top of B4, B8 and B12-buildings. The SAFs were computed using simply the ratio of spectra of the horizontal component of SV-wave at the top of building and that on the exposed rock. Analysis of Fig. 2 revealed a decrease of value of $S V F_{02 D}^{S}$ of the BBM on rock with an increase of height for a fixed dimension of base (Kumar and Narayan, 2018). The numerically obtained of the B12, B8 and B4-buildings for the SV-wave were $0.66 \mathrm{~Hz}, 1.06 \mathrm{~Hz}$ and $2.34 \mathrm{~Hz}$, respectively (Table 2). The inferred increase of rate of decrease of of BBM with height may be due to decrease of bending stiffness of building.

\subsection{Effects of IC on the response of standalone BBM on rock}

In order to study the role of IC at base of basin in the SCI effects on the $\mathrm{SH}-$ and SV-wave responses of buildings and basin, four ICSH1-ICSH4 sitecity models for the SH-wave and four ICSV1-ICSV4 site-city models for the SV-wave simulations were taken (Table 3). In all the IC models, only the impedance of rock is varied and the rheological parameters of the basin and buildings are same.

Table 3. The rheological parameters of rock for the ICSH1-ICSH4 and ICSV1-ICSV4 site-city models and impedance contrast at the base of basin and building situated on rock (Note: basin and BBM parameters are given in Table 1).

\begin{tabular}{|c|c|c|c|c|c|c|c|}
\hline $\begin{array}{c}\text { Site-city } \\
\text { models }\end{array}$ & $\begin{array}{c}V_{S} \\
(\mathrm{~m} / \mathrm{s})\end{array}$ & $\begin{array}{c}V_{P} \\
(\mathrm{~m} / \mathrm{s})\end{array}$ & $\begin{array}{c}\text { Density } \\
\left(\mathrm{g} / \mathrm{cm}^{3}\right)\end{array}$ & $\begin{array}{c}\text { Quality } \\
\text { factor }\left(Q_{S}\right)\end{array}$ & $\begin{array}{c}\text { Quality } \\
\text { factor }\left(Q_{P}\right)\end{array}$ & $\begin{array}{c}\text { IC at base } \\
\text { of basin }\end{array}$ & $\begin{array}{c}\text { IC at base } \\
\text { of BBM }\end{array}$ \\
\hline ICSH1/ICSV1 & 1800 & 3117.7 & 2.50 & 180 & 311 & 8.33 & 107.14 \\
\hline ICSH2/ICSV2 & 1600 & 2771.3 & 2.30 & 160 & 277 & 6.81 & 87.62 \\
\hline ICSH3/ICSV3 & 1400 & 2424.9 & 2.10 & 140 & 242 & 5.44 & 70.00 \\
\hline ICSH4/ICSV4 & 1200 & 2078.5 & 2.00 & 120 & 208 & 4.44 & 57.14 \\
\hline
\end{tabular}

\subsubsection{SH-wave responses}

The SH-wave responses of the standalone B16-BBM on the rock were computed using the rheological parameters of the rock of the ICSH1-ICSH4 site-city models (Table 3). The computed SAFs of the SH-wave at the top of B16-BBM for different rock impedances are shown in the left panel of 
Fig. 3a. There is an excellent match of numerically obtained $S H F_{02 D}^{S}$ of building as $0.62 \mathrm{~Hz}$ with that computed using simple relationship $F_{02 D}^{S}=$ $V_{S} / 4 H$, since the BBM is behaving as a shear beam model (Guéguen et al., 2019; Kumar and Narayan, 2018; 2019). The obtained SAFs at $S H F_{02 D}^{S}$ of the B16-BBM as 11.38, 11.33, 11.28 and 11.21 in the ICSH1-ICSH4 models, respectively revealed that $\mathrm{SAF}$ at $S H F_{02 D}^{S}$ was almost unaffected by the change of IC at the base of building, although corresponding ICs were 107.14, 87.62, 70.0 and 57.14, respectively (Table 3).
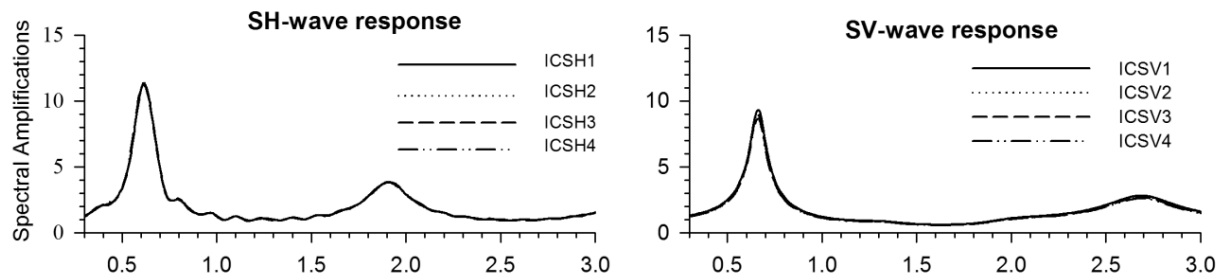

(a) Standalone building on rock
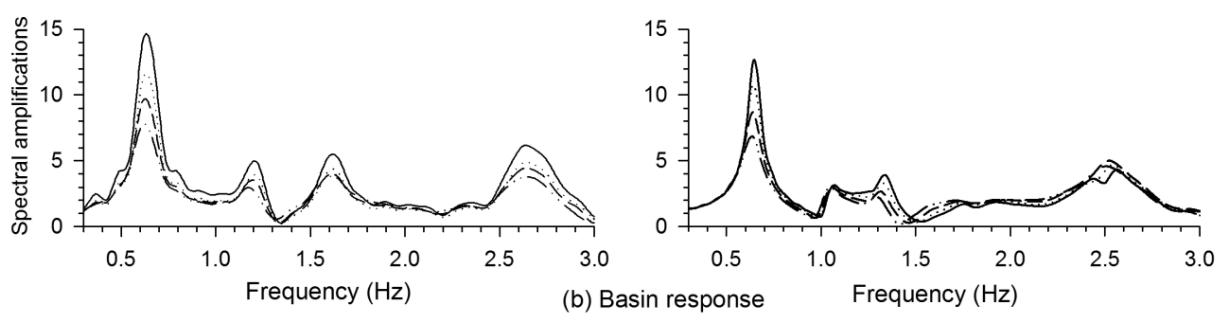

Fig. 3a-b. spectral amplifications at the top of standalone building on rock and free field motion in basin in the absence of city with impedances in the rock corresponding to the ICSH1/ICSV1-ICSH4/ICSV4, respectively.

\subsubsection{SV-wave response}

Similarly, the SV-wave responses of the standalone B12-BBM on the rock were computed using the rheological parameters of the rock of the ICSV1ICSV4 site-city models (Table 3). The computed SAFs of the horizontal component of SV-wave at the top of B12-BBM for different rock impedances are shown in the right panel of Fig. 3a. A comparison of the numerically obtained $S V F_{02 D}^{S}$ of building $(0.66 \mathrm{~Hz})$ with that computed using simple relationship $F_{02 D}^{S}=V_{S} / 4 H(0.83 \mathrm{~Hz})$ reveals a drastic decrease of $S V F_{02 D}^{S}$ of the B12-BBM, since for the $\mathrm{SV}$-wave, the BBM is behaving as a bending beam model (Guéguen et al., 2019; Kumar and Narayan, 2018; 2019). The 
obtained SAFs at $S V F_{02 D}^{S}$ of the B12 building as 9.18, 8.97, 8.76 and 8.61 in the ICSV1-ICSV4 models, respectively revealed that SAF at $S V F_{02 D}^{S}$ was almost unaffected by the change of IC at the base of building (Table 3). These findings depicted that the $5 \%$ damping in the BBM has controlled the SAF at fundamental frequency and not the IC between the BBM and the underlying rock. Further, the obtained fundamental frequency of the $\mathrm{BBM}$ for the $\mathrm{SH}$-wave $(0.62 \mathrm{~Hz})$ and $\mathrm{SV}$-wave $(0.66 \mathrm{~Hz})$ were same in all the respective IC models.

\section{Response of elliptical basin}

The computed $S H F_{02 D}^{S}$ of the B16-BBM as $0.62 \mathrm{~Hz}$ and $S H F_{02 D}^{S}$ of B12-BBM as $0.66 \mathrm{~Hz}$ in the case of all the IC models depict that the fundamental frequency of elliptical basin for the $\mathrm{SH}$-wave $\left(S H F_{02 D}^{B}\right)$ and $\mathrm{SV}$-wave $\left(S V F_{02 D}^{B}\right)$ should also be $0.62 \mathrm{~Hz}$ and $0.66 \mathrm{~Hz}$, respectively to preserve the double resonance condition. Bard and Bouchon (1985) reported that the fundamental frequency of deep-elliptical basin for the SH-wave is lesser than for the SVwave for a particular dimension of basin. In case of deep-basin, the entire basin vibrates with a single fundamental frequency and there is an increase of $F_{02 D}^{B}$ of basin with an increase of IC (Bard and Bouchon, 1985; Kumar and Narayan, 2018; Zhu et al., 2019).

\subsection{SH-wave response of basin}

Kumar and Narayan (2018) have given an empirical relation to predict the $S H F_{02 D}^{B}$ of deep-basin in terms of lowest 1D fundamental frequency $\left(F_{01 D}^{B}\right)$ and maximum depth ' $h$ ' for the SH-wave.

$S H F_{02 D}^{B}=F_{01 D}^{B} \sqrt{1+1.6\left(\frac{h}{w}\right)^{2}}$,

where $F_{01 D}^{B}=V_{S} / 4 h$, ' $h$ ' and ' $w$ ' are the 1 D lowest fundamental frequency, maximum depth and half-width of the elliptical basin, respectively. The estimated maximum depth and width $(2 w)$ of elliptical basin for $S_{H F}{ }_{02 D}^{B}=$ $0.62 \mathrm{~Hz}$ are $150 \mathrm{~m}$ and $492 \mathrm{~m}$, respectively, using Eq. (2). In order to find out the variation of $S H F_{02 D}^{B}$ of basin with IC, the $\mathrm{SH}$-wave responses of the elliptical basin with depth $150 \mathrm{~m}$ and width $492 \mathrm{~m}$ were computed for 
all the IC models. The left panel of Fig. 3b show the SAFs at a distance of $39 \mathrm{~m}$ from the centre of elliptical basin with ICs corresponding to the ICSH1-ICSH4 site-city models. An analysis of Fig. 3b revealed that there is minor increase of $S H F_{02 D}^{B}$ of basin with an increase of IC at its base (Zhu et al., 2019; Kumar and Narayan, 2018). For example, the obtained $S H F_{02 D}^{B}$ of elliptical basin are $0.638 \mathrm{~Hz}, 0.627 \mathrm{~Hz}, 0.626 \mathrm{~Hz}$ and $0.621 \mathrm{~Hz}$ in the ICSH1-ICSH4 models, respectively. There is minor mismatch of $S H F_{02 D}^{S}$ of building with $S H F_{02 D}^{B}$ of basin in the case of larger IC values.

\subsection{SV-wave response of basin}

Bard and Bouchon (1985) have given an empirical relation to predict the $S V F_{02 D}^{B}$ of deep-basin in terms of lowest 1D fundamental frequency $\left(F_{01 D}^{B}\right)$ for the SV-wave (Zhu et al., 2019).

$$
S V F_{02 D}^{B}=F_{01 D}^{B} \sqrt{1+\left(\frac{2.9 h}{w_{e}}\right)^{2}},
$$

where ' $2 w_{e}$ ' is the effective width of basin (effective width is the span over which the depth $(h)$ is $\geq h / 2$ ). The inferred depth, width and effective width of the elliptical basin for $S V F_{02 D}^{B}=0.66 \mathrm{~Hz}$ are $150 \mathrm{~m}, 660 \mathrm{~m}$ and $505 \mathrm{~m}$, respectively, using Eq. (3). To infer the variation of $S V F_{02 D}^{B}$ with IC, the $\mathrm{SV}$-wave responses of the elliptical basin with maximum depth $150 \mathrm{~m}$ and width $660 \mathrm{~m}$ were computed for all the IC models. The right panel of Fig. 3b shows the SAFs at a distance of $36 \mathrm{~m}$ from the centre of elliptical basin with IC corresponding to the ICSV1-ICSV4 site-city models. Fig. 3b also revealed an increase of $S V F_{02 D}^{B}$ of the elliptical basin with an increase of IC (Zhu et al., 2019; Kumar and Narayan, 2018). The numerically obtained $S V F_{02 D}^{B}$ of elliptical basin as $0.662 \mathrm{~Hz}, 0.658 \mathrm{~Hz}, 0.655 \mathrm{~Hz}$ and $0.651 \mathrm{~Hz}$ in the ICSV1-ICSV4 models, respectively revealed a minor mismatch with the $S V F_{02 D}^{S}$ of structure $(0.66 \mathrm{~Hz})$ in the case of lower IC models.

\section{Role of IC in SCI effects on SH-wave responses}

In all the considered ICSH1-ICSH4 site-city models, five-B16 buildings of width $60 \mathrm{~m}$ are situated at an equal spacing of $15 \mathrm{~m}$ in the elliptical basin. 
The centre of $3^{\text {rd }}$ building is at the centre of basin and the width of city is $360 \mathrm{~m}$. The $\mathrm{SH}$-wave responses of a standalone building at the centre of elliptical basin are used as a reference one to quantify the SCI effects on the response of buildings of the city. Similarly, the response of basin at some selected locations in the absence of city were considered as a reference one to quantify the SCI effects on the response of basin.

\subsection{Standalone building at the centre of elliptical basin}

The left and right panels of Fig. 4a depict the SH-wave responses at the top of standalone building situated at centre of elliptical basin and corresponding spectral amplifications, respectively in the case of ICSH1-ICSH4 site-city models. Analysis of Fig. 4a illustrated an increase of amplitude of the SHwave with a decrease of impedance in the rock. This may be due to use of the same stress drop to generate point sources in all the IC models. The computed fundamental frequency of standalone building in basin $\left(S H F_{02 D}^{S B}\right)$ as $0.61 \mathrm{~Hz}$ in all the IC models depicts that $S H F_{02 D}^{S B}$ of building is not affected by IC. The achieved SAF at $S H F_{02 D}^{S B}$ of building as $51.89,48.92,44.85$ and 40.95 were $4.5,4.3,3.9$ and 3.6 times larger than that on $F_{02 D}^{S}$ of standalone building on rock in the ICSH1-ICSH4 site-city models, respectively. The
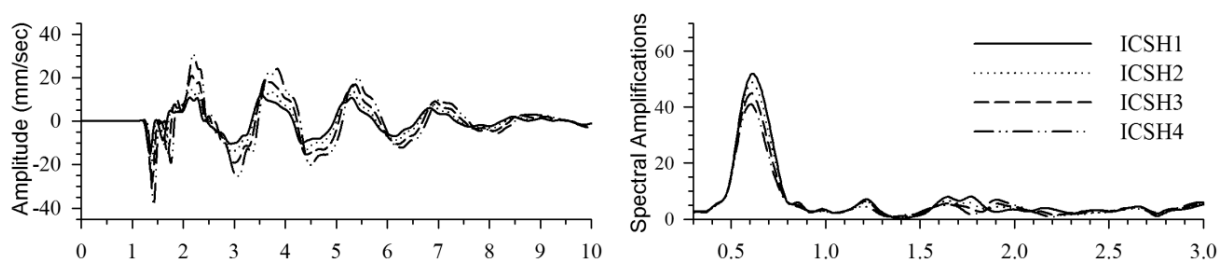

(a) Standalone building in basin
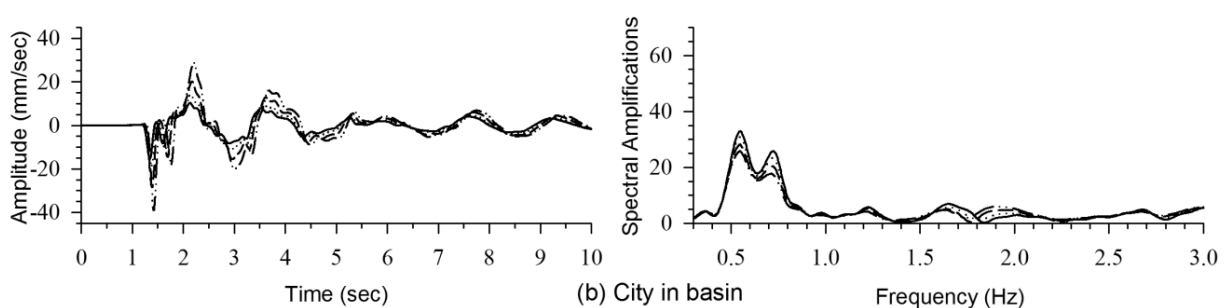

Fig. 4a-b. The SH-wave responses (left panels) and spectral amplifications (right panels) at the top of standalone building situated at the centre of elliptical basin and at the top of the building situated at the centre of city, respectively. 
observed very large amplification at the top of standalone building in basin as compared to the standalone building on rock revealed effect of occurrence of double resonance phenomenon.

\subsection{City situated in the elliptical basin}

In this numerical experiment, the $\mathrm{SH}$-wave responses of buildings of the ICSH1-ICSH4 site-city models as well as free field motion have been simulated and analysed.

\subsubsection{SCI effects on the response of buildings}

The SH-wave responses and corresponding SAFs at the top of $3^{\text {rd }}$ building of the ICSH1-ICSH4 site-city models is shown in the left and right panels of Fig. 4b. It is very much clear that the SCI has caused reduction of the amplitude of SH-wave, particularly in the case of later phases as compared to the respective response of standalone building in basin. The obtained $S H F_{02 D}^{S B}$ of the $3^{\text {rd }}$ building as $0.55 \mathrm{~Hz}$ in all the IC models revealed that $S H F_{02 D}^{S B}$ of building is almost not affected by IC. However, there is $9.8 \%$ reduction of $S H F_{02 D}^{S B}$ due to the SCI effects. The obtained SAFs at $S H F_{02 D}^{S B}$ of $3^{\text {rd }}$ building as $33.23,31.41,28.85$ and 26.67 in the case of ICSH1-ICSH4 site-city models, respectively, revealed an increase of SAFs at $S H F_{02 D}^{S B}$ of building with an increase of IC. Table 4 reveals that SCI effects due to only 5buildings have caused $35.96 \%, 35.79 \%, 35.67 \%$ and $34.87 \%$ reduction of SAF at $S H F_{02 D}^{S B}$ of building in the ICSH1-ICSH4 site-city models, respectively.

Similarly, the observed $\%$ reduction of SAF at $F_{02 D}^{S}$ of $3^{\text {rd }}$ building as $60.37 \%, 59.95 \%, 59.21 \%$ and $57.60 \%$ in the ICSH1-ICSH4 site-city models, respectively revealed that the reduction of $\mathrm{SAF}$ at $S H F_{02 D}^{S}$ was larger than that at $S H F_{02 D}^{S B}$ of the $3^{\text {rd }}$ building of the respective site-city model (Table 4). The larger $\%$ reduction of SAF at frequency $S H F_{02 D}^{S}$ may be due to the additional reduction of $\mathrm{SAF}$ at $S H F_{02 D}^{S}$ caused by the seismic waves emanated by the buildings during their inertial vibrations. The emanated seismic waves during inertial vibrations were out of phase to that of the incident SH-wave. There is only minor increase in \% reduction of SAFs at $S H F_{02 D}^{S B}$ and $S H F_{02 D}^{S}$ with an increase of IC (Table 4). Further, the effects of minor mismatch of $S H F_{02 D}^{S}$ with $S H F_{02 D}^{B}$ has no considerable effects on the response of buildings. 
Table 4. A comparisons of SAFs at $F_{02 D}^{S B}$ and $F_{02 D}^{S}$ in the case of standalone building and $3^{\text {rd }}$ building of city in basin and corresponding \% reduction of SAFs at $F_{02 D}^{S B}$ and $F_{02 D}^{S}$ due to the SCI effects in the ICSH1-ICSH4 and ICSV1-ICSV4 site-city models.

\begin{tabular}{|l|c|c|c|c|}
\hline Site-city models & ICSH1 & ICSH2 & ICSH3 & ICSH4 \\
\hline SAF at $S H F_{02 D}^{S B}$ of standalone building in basin & 51.89 & 48.92 & 44.85 & 40.95 \\
\hline SAF at $S H F_{02 D}^{S B}$ of 3rd building of city & 33.23 & 31.41 & 28.85 & 26.67 \\
\hline$\%$ reduction of SAF at $S H F_{02 D}^{S B}$ of 3rd building & 35.96 & 35.79 & 35.69 & 34.87 \\
\hline SAF at $S H F_{02 D}^{S}$ of standalone building in basin & 51.78 & 48.64 & 44.37 & 40.38 \\
\hline SAF at $S H F_{02 D}^{S}$ of 3rd building of city & 20.56 & 19.59 & 18.29 & 17.36 \\
\hline$\%$ reduction of SAF at $S H F_{02 D}^{S}$ of 3rd building & 60.37 & 59.95 & 59.21 & 57.60 \\
\hline \hline Site-city models & ICSV1 & ICSV2 & ICSV3 & ICSV4 \\
\hline SAF at $S V F_{02 D}^{S B}$ standalone building in basin & 67.27 & 59.69 & 50.61 & 41.82 \\
\hline SAF at $S V F_{02 D}^{S B}$ of 5 th building of city & 34.41 & 31.02 & 26.90 & 22.65 \\
\hline$\%$ reduction of SAF at $S V F_{02 D}^{S B}$ of 5 th building & 48.84 & 48.03 & 46.84 & 45.83 \\
\hline SAF at $S V F_{02 D}^{S}$ standalone building in basin & 61.50 & 54.20 & 45.80 & 37.63 \\
\hline SAF at $S V F_{02 D}^{S}$ of 5 th building of city & 20.04 & 18.81 & 17.18 & 15.31 \\
\hline$\%$ reduction of SAF at $S V F_{02 D}^{S}$ of 5 th building & 67.41 & 65.29 & 62.48 & 59.31 \\
\hline
\end{tabular}

The left and right panels of Fig. 5a-d depict the SH-wave responses and the spectral amplifications at the top of $1^{\text {st }}, 2^{\text {nd }}$ and $3^{\text {rd }}$ buildings of the ICSH1-ICSH4 site-city models, respectively. As expected, a decrease of amplitude of the SH-wave at the top of $1^{\text {st }}, 2^{\text {nd }}$ and $3^{\text {rd }}$ buildings can be inferred due to an increase of impedance in the rock. Relatively larger decrease of amplitude of the SH-wave at the top of buildings situated away from the centre of city can be observed. This may be due to the decrease of basin response at its fundamental frequency (Bard and Bouchon, 1985; Kumar and Narayan, 2018). An increase of spectral amplifications at the top of buildings with the increase of IC can be inferred. Fig. 5 also depicts the decrease of SAF at $S H F_{02 D}^{S B}$ of building towards the edge of city. However, this decrease was very large in case of the $1^{\text {st }}$ building. For example, the largest SAF obtained at $S H F_{02 D}^{S B}$ of building at the top of $1^{\text {st }}, 2^{\text {nd }}$ and $3^{\text {rd }}$ buildings of the ICSH3 site-city model as 12.31, 23.86 and 28.85, respectively were $72.55 \%, 46.80$ and $35.69 \%$ lesser as compared to the SAF obtained at the top of standalone building at the centre of the ICB3 model. Further, in the case of ICSH3 model, the obtained \% reduction of SAF at 

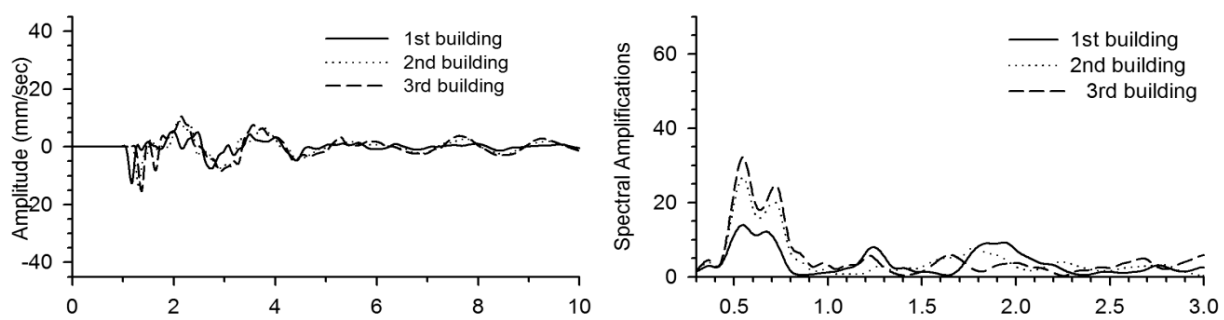

(a) ICSH1 Site-city model
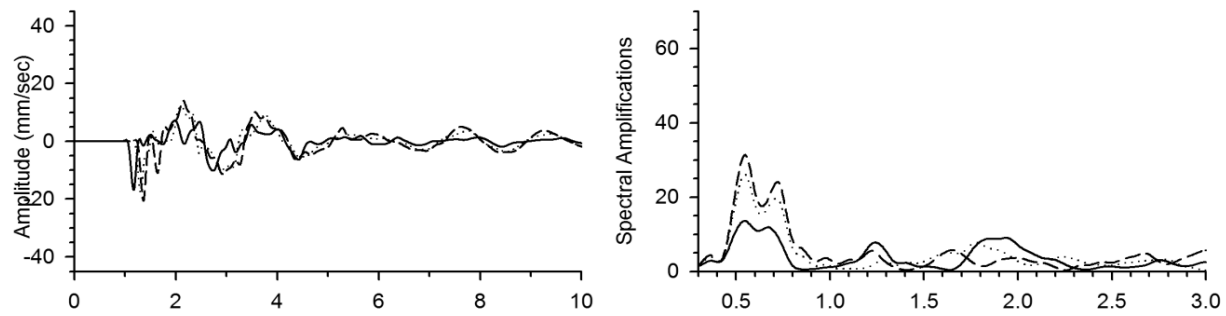

(b) ICSH2 Site-city model
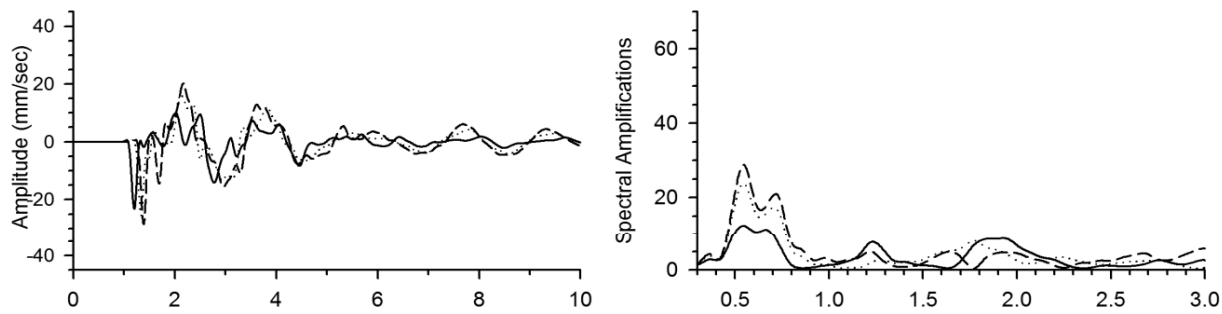

(c) ICSH3 Site-city model
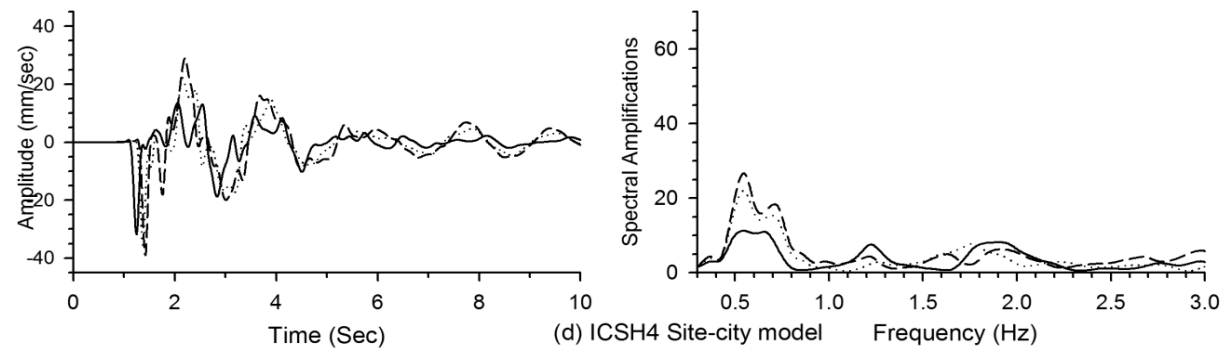

Fig. 5a-d. The SH-wave responses at the top of $1^{\text {st }}, 2^{\text {nd }}$ and $3^{\text {rd }}$ buildings of the ICSH1ICSH4 site-city models, respectively (left panels) and corresponding spectral amplifications (right panels). 
$S H F_{02 D}^{S}$ at the top of $1^{\text {st }}, 2^{\text {nd }}$ and $3^{\text {rd }}$ buildings as $76.17 \%, 64.93$ and $59.21 \%$ were larger as compared to the \% reduction of SAF at $S H F_{02 D}^{S B}$ of the respective building (Table 4). But, it may not be concluded that there were larger SCI effects on the responses of $1^{\text {st }}$ and $2^{\text {nd }}$ buildings as compared to the $3^{\text {rd }}$ building. This was due to the computation of $\%$ reduction of SAF at $S H F_{02 D}^{S B}$ with respect to the reference standalone building situated at the centre of basin.

\subsubsection{SCI effects on free field motion}

To quantify the role of IC in the SCI effects on the response of basin, the $\mathrm{SH}$-wave responses at different locations in the elliptical basin for without and with city in basin were computed for the ICSH1-ICSH4 site-city models. The selected locations in the basin were at a distance of $39 \mathrm{~m}, 114 \mathrm{~m}$ and $189 \mathrm{~m}$ towards the right of centre of basin (third receiver point was $9 \mathrm{~m}$ away from the edge of city). Fig. 6a-d depicts the comparison of spectral amplifications computed for with and without ICSH1-ICSH4 site-city models at different locations. Analysis of Fig. 6 revealed a decrease of spectral amplifications due to the SCI effects. The basin was vibrating with a single resonance frequency $(0.53 \mathrm{~Hz})$ in the presence of city in all the IC models. In contrast to this, there was minor increase of $S H F_{02 D}^{B}$ of basin with an increase of IC in the absence of city. Further, the obtained decrease of SAF at $S H F_{02 D}^{B}$ towards the edge of basin corroborates with the finding of Bard and Bouchon (1985). It was interesting to note the decrease of $S H F_{02 D}^{B}$ of basin due to the SCI effects. The obtained $S H F_{02 D}^{B}$ of basin $(0.53 \mathrm{~Hz})$ due to SCI effects was somewhat lesser than $S H F_{02 D}^{S B}$ of building $(0.55 \mathrm{~Hz})$ of city.

Table 5 shows that the $\%$ age reduction of $\mathrm{SAF}$ at $S H F_{02 D}^{B}$ of basin as compared to that in the absence of city is increasing with increase of IC. Further, the $\%$ age reduction of SAF at $S H F_{02 D}^{B}$ of basin was decreasing towards the edge of city. For example, the obtained SAF at $S H F_{02 D}^{B}$ as 7.31, $6.22,2.30$ at $39 \mathrm{~m}, 114 \mathrm{~m}$ and $189 \mathrm{~m}$ distance from the centre of basin in the ICSH1 model was $50.40 \%, 35.27 \%$ and $33.90 \%$ lesser than that obtained in the absence of city. The computed $\%$ reduction of average spectral amplification (ASA) at a distance of $39 \mathrm{~m}$ as $11.4 \%, 10.11 \%, 9.42 \%$ and $8.26 \%$ as well as at a distance of $189 \mathrm{~m}$ (outside city) as $5.38 \%, 5.23 \%, 4.90 \%$ and $4.00 \%$ in the ICSH1-ICSH4 site-city models, respectively was also an 

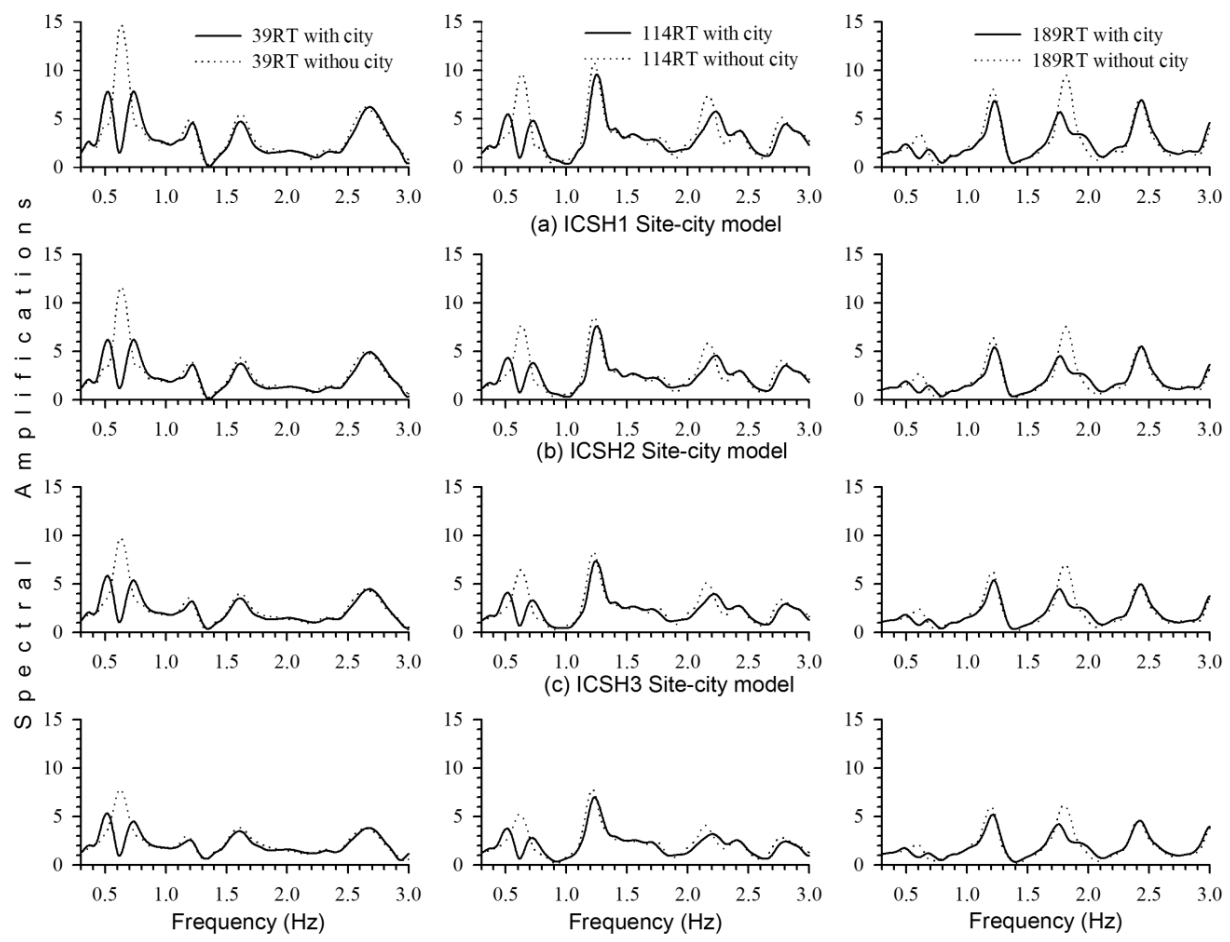

(a) ICSH1 Site-city model
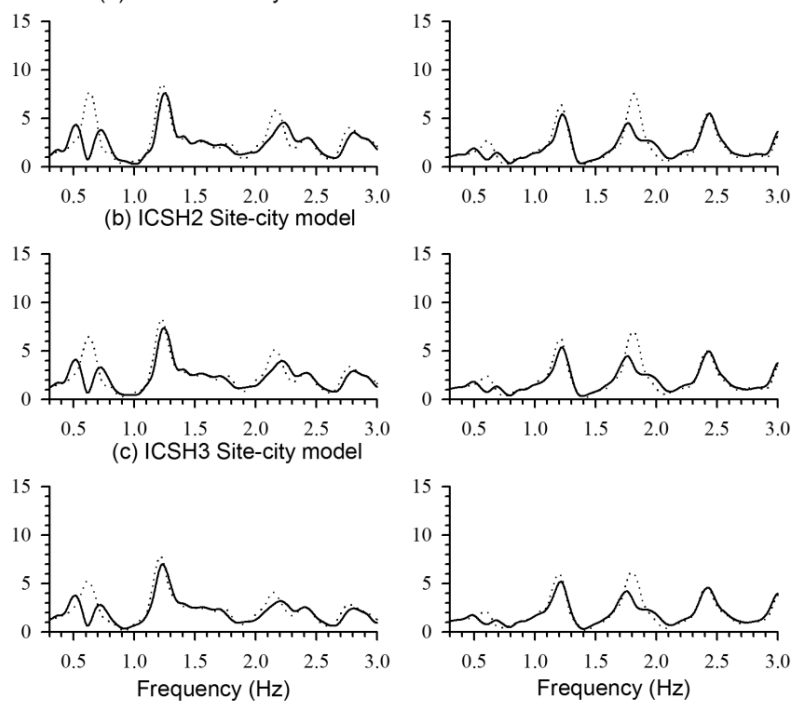

(d) ICSH4 Site-city model

Fig. 6a-d. A comparison of spectral amplifications at different locations in the elliptical basin corresponding to with and without city in basin in the ICSH1-ICSH4 site-city models, respectively.

indicator that SCI effect was largest at the centre of city and decreasing towards the edge or outside the city (ASA is simply the average of spectral amplifications in the considered frequency bandwidth). The larger reduction of SAF at frequency $S H F_{02 D}^{S}$ was responsible for the splitting of the bandwidth of the fundamental mode of vibration of basin as was inferred in the case of building's response. The \% reduction of $\mathrm{SAF}$ at $S H F_{02 D}^{S}$ is also increasing with increase of IC.

\section{Role of IC in SCI effects on SV-wave responses}

To quantify the role of IC in the SCI effects on the SV-wave responses of buildings and the basin, four ICSV1-ICSV4 site-city models were consid- 
Table 5. A comparison of SAFs at $F_{02 D}^{B}$ of basin as well as ASA of free field motion for without and with city in basin and corresponding \% reductions due to the SCI effects in the ICSH1-ICSH4 and ICSV1-ICSV4 site-city models.

\begin{tabular}{|l|c|c|c|c|}
\hline Site-city models & ICSH1 & ICSH2 & ICSH3 & ICSH4 \\
\hline SAF at $S H F_{02 D}^{B}$ for without city at $39 \mathrm{~m}$ & 13.74 & 11.58 & 9.51 & 7.71 \\
\hline SAF at $S H F_{02 D}^{B}$ for with city at $39 \mathrm{~m}$ & 7.31 & 6.23 & 5.24 & 4.82 \\
\hline$\%$ reduction in SAF at $S H F_{02 D}^{B}$ at $39 \mathrm{~m}$ & 50.40 & 46.20 & 44.84 & 37.48 \\
\hline $\mathrm{ASA}$ at $39 \mathrm{~m}$ for without city & 3.24 & 2.57 & 2.44 & 2.30 \\
\hline $\mathrm{ASA}$ at $39 \mathrm{~m}$ for with city & 2.87 & 2.31 & 2.21 & 2.11 \\
\hline$\%$ Decrease in ASA at $39 \mathrm{~m}$ & 11.40 & 10.11 & 9.42 & 8.26 \\
\hline \hline Site-city $m o d e l s$ & ICSV1 & ICSV2 & ICSV3 & ICSV4 \\
\hline SAF at $S V F_{02 D}^{B}$ for without city at $36 \mathrm{~m}$ & 12.54 & 10.76 & 8.69 & 6.82 \\
\hline SAF at $S V F_{02 D}^{B}$ for with city at $36 \mathrm{~m}$ & 7.62 & 7.44 & 6.46 & 5.45 \\
\hline$\%$ reduction in SAF at $S V F_{02 D}^{B}$ at $36 \mathrm{~m}$ & 39.23 & 30.85 & 25.43 & 20.08 \\
\hline $\mathrm{ASA}$ at $36 \mathrm{~m}$ for without city & 2.46 & 2.43 & 2.41 & 2.27 \\
\hline $\mathrm{ASA}$ at $36 \mathrm{~m}$ for with city & 2.06 & 2.07 & 2.09 & 2.01 \\
\hline$\%$ Decrease in ASA at $36 \mathrm{~m}$ & 16.26 & 14.81 & 13.27 & 11.45 \\
\hline
\end{tabular}

ered (Tables 1-3). Fig. 1 illustrates the sketch for the vertically exaggerated site-city model with nine B12-buildings situated in the elliptical basin. The maximum depth and width of the elliptical basin were taken as $150 \mathrm{~m}$ and $660 \mathrm{~m}$, respectively. The width of B12 buildings was taken as $60 \mathrm{~m}$ and spacing between two consecutive buildings was $12 \mathrm{~m}$. The buildings of the city were numbered as $1^{\text {st }}, 2^{\text {nd }}$ and $9^{\text {th }}$ building from left to right edge of the city. The centre of $5^{\text {th }}$ building was at the centre of elliptical basin. The free field motions were computed on a horizontal array with 14-equidistant (72 $\mathrm{m}$ apart) receiver points, extending from $486 \mathrm{~m}$ left to $468 \mathrm{~m}$ right of the centre of elliptical basin.

\subsection{Standalone building at the centre of basin}

To quantify the SCI effects on the response of B12-buildings of the city, the SV-wave response of standalone B12-building at the centre of elliptical basin is considered as a reference one. Fig. 7a shows a comparison of horizontal component of the SV-wave responses at the top of standalone B12-building situated at the centre of basin (left panel) and corresponding 
SAFs (right panel) in the ICSV1-ICSV4 impedance models. The double resonance phenomenon was responsible for many fold increase in spectral amplifications. For example, the obtained SAFs at $S V F_{02 D}^{S B}$ as $67.27,59.69$, 50.61 and 41.82 in the ICSV1-ICSV4 models were 7.32, 6.65, 5.77 and 4.91 times larger than those obtained at $S V F_{02 D}^{S}$ of building on rock, respectively (Table 4). Although, there was no increase of $S V F_{02 D}^{S B}$ of building with an increase of IC, but, the interaction of standalone building with basin has caused a minor reduction of $S V F_{02 D}^{S B}$ of building $(0.64 \mathrm{~Hz})$ as compared to the $S V F_{02 D}^{S}$ of standalone building on rock $(0.66 \mathrm{~Hz})$. There is no splitting of the spectral bandwidth of the fundamental mode of vibration of building.
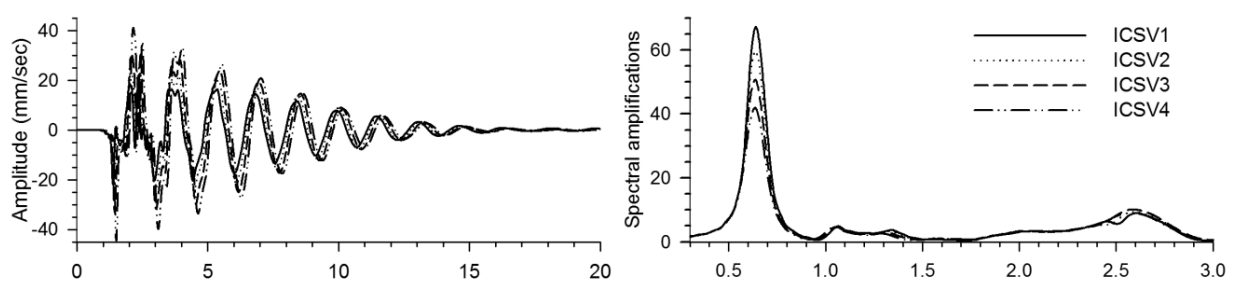

(a). Standalone building in basin
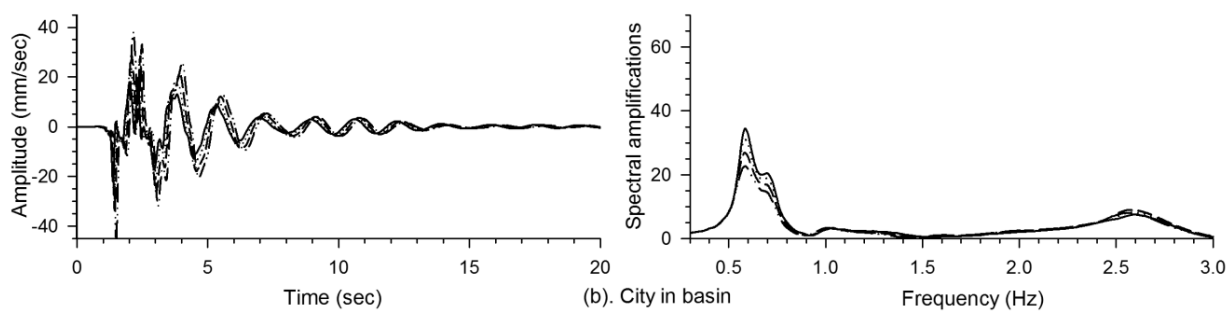

Fig. 7a-b. A comparison of the SV-wave responses (left) and spectral amplifications (right) at the top of standalone building on the exposed rock, at the top of a standalone building at the centre of basin and at the top of a building situated at the centre of ICSV1-ICSV4 site-city models, respectively.

\subsection{SCI effects on building response}

The left panel of Fig. 7b shows the SV-wave responses at the top of $5^{\text {th }}$ building of the ICSV1-ICSV4 site-city models. Fig. 7b revealed a decrease of amplitude and duration of the SV-wave at the top of building with an increase of IC. In contrast to this, the right panel of Fig. $7 \mathrm{~b}$ showed that the SAFs at the top of building were increasing with the increase of IC. The 
interaction of city with basin has further reduced the $S V F_{02 D}^{S B}$ of building to $0.58 \mathrm{~Hz}$, but, this reduction was not affected by the change of IC. The obtained SAF at $S V F_{02 D}^{S B}$ of $5^{\text {th }}$ building as 34.41, 31.02, 26.90 and 22.65 in the ICSV1-ICSV4 site-city models, respectively were $48.84 \%, 48.03 \%$, $46.84 \%$ and $45.43 \%$ lesser than those obtained in the respective case of the standalone building (Table 4).

On the other hand, the observed reduction of SAF at $S V F_{02 D}^{S}$ of building as $67.41 \%, 65.29 \%, 62.48 \%$ and $59.31 \%$ in the ICSV1-ICSV4 site-city models, respectively revealed that reduction of SAF at $S V F_{02 D}^{S}$ was larger than that at $S V F_{02 D}^{S B}$ (Table 4). There was also an increase of \% reduction in ASA in the horizontal component of SV-wave response of $5^{\text {th }}$ building with an increase of IC as compared to that in the case of standalone building. So, it may be inferred that the role of IC in the SCI effects on the building response is considerable but not on the reduction of $S V F_{02 D}^{S B}$ of buildings.

The left and right panels of Fig. 8a-d depict a comparison of the SV-wave responses and SAFs at the top of $5^{\text {th }}, 7^{\text {th }}$ and $9^{\text {th }}$ buildings of the ICSV1ICSV4 site-city models, respectively. A decrease of the SV-wave amplitude and duration at the top of buildings towards the edge of city can be inferred. A decrease of SAFs at the top of building with the decrease of impedance in rock as well as towards the edge of city can be seen in the right panels of Fig. 8a-d. Fig. 8 also showed a decrease of SAF at frequency $S V F_{02 D}^{S B}$ towards the edge of city, but this decrease was very large in the case of $9^{\text {th }}$ building. This may be due to decrease of SAF at towards the edge (Bard and Bouchon, 1985; Kumar and Narayan, 2018).

\subsection{SCI effects on basin response}

The SV-wave responses of the ICSV1-ICSV4 site-city models for without and with city in basin were computed on the horizontal array in between the buildings to quantify the role of IC in SCI effects on the SV-wave response of basin. A considerable decrease in the SV-wave response of basin was inferred due to the presence of city (result not shown here). Fig. 9a-d depicts the comparison of SAFs of the horizontal component of the SV-wave for without and with city in the basin at a distance of $36 \mathrm{~m}$ (left panel), $108 \mathrm{~m}$ (middle panel), and $252 \mathrm{~m}$ (right panel) from the centre of basin for the ICSV1ICSV4 site-city models, respectively. The analysis of Fig. 9 revealed that 
in the absence of city, the deep elliptical basin was vibrating with a single fundamental frequency and the amplification at this frequency was largest at the centre of basin and reduced to one towards the edge of basin, as was observed in the case of SH-wave responses (Bard and Bouchon, 1985; Kumar and Narayan, 2018).
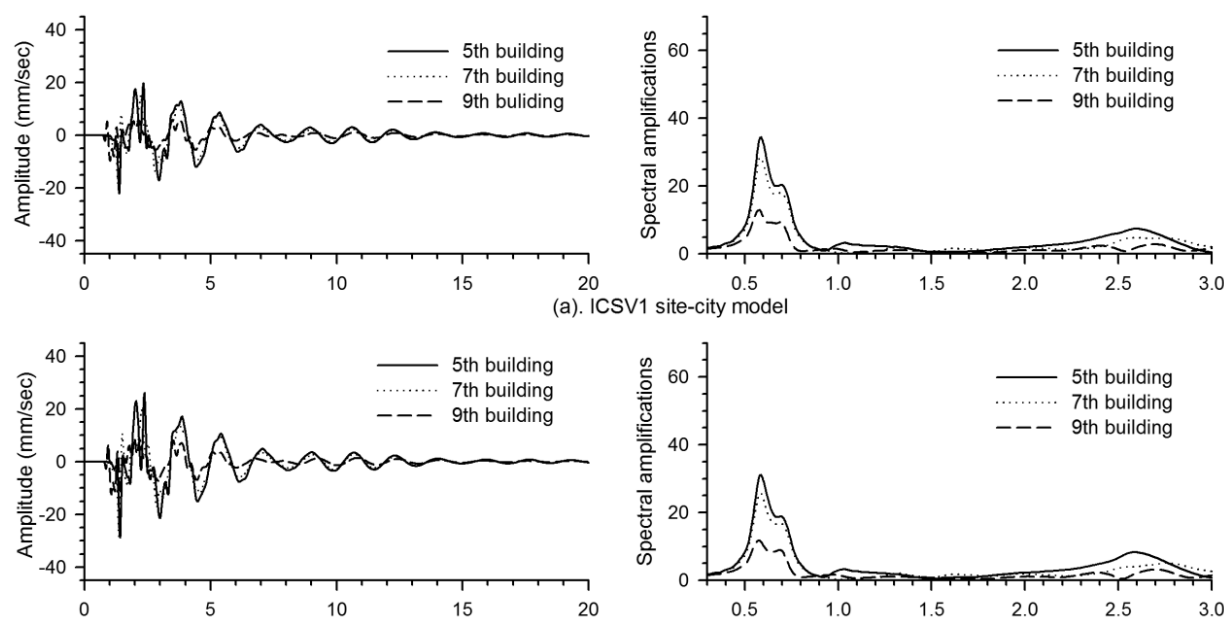

(b). ICSV2 site-city model
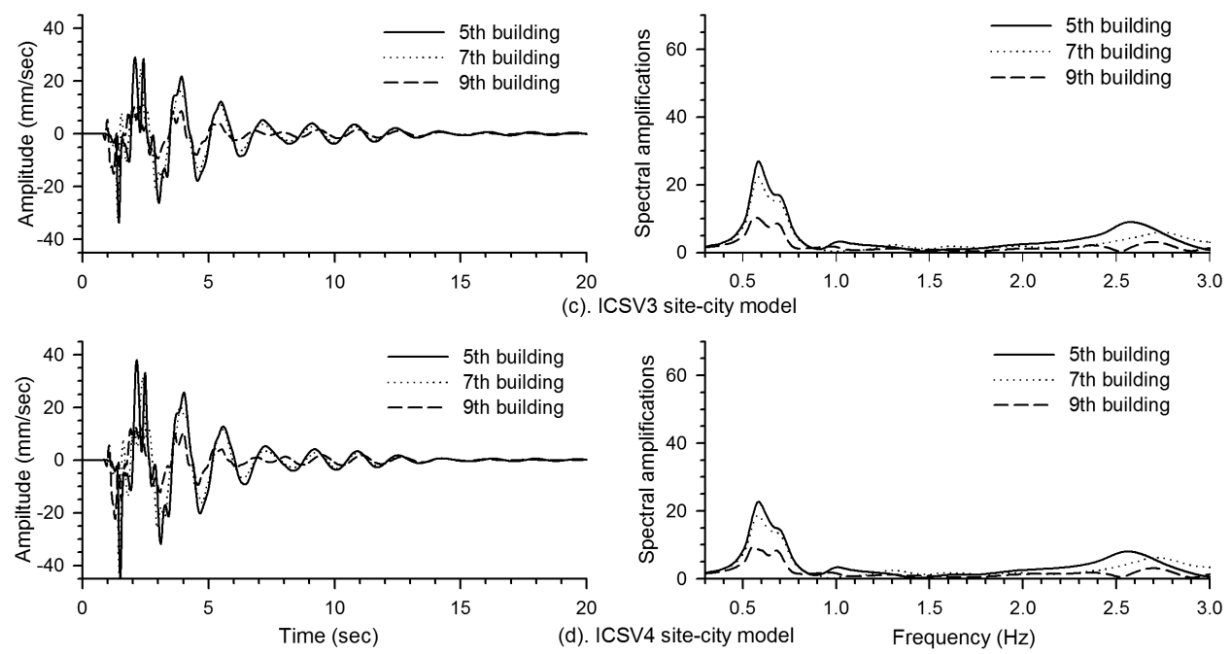

Fig. 8a-d. A comparison of the SV-wave responses (left) and spectral amplifications (right) at the top of different buildings of the ICSV1-ICSV4 site-city models, respectively. 

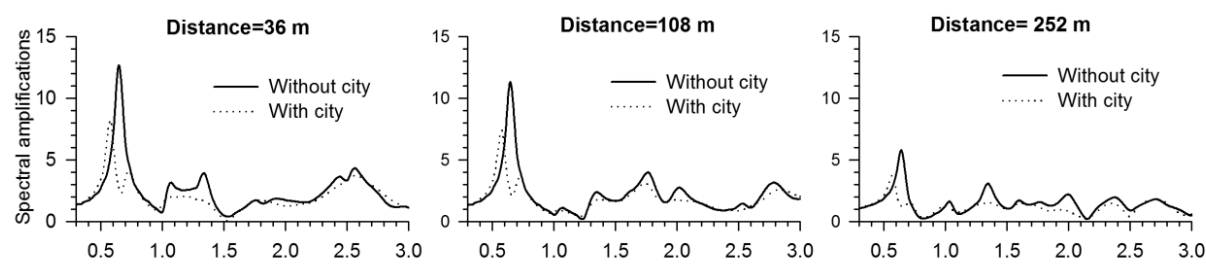

(a). ICSV1 site-city model
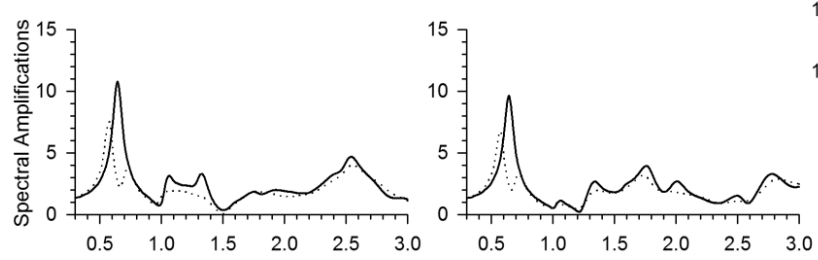

(b). ICSV2 site-city model
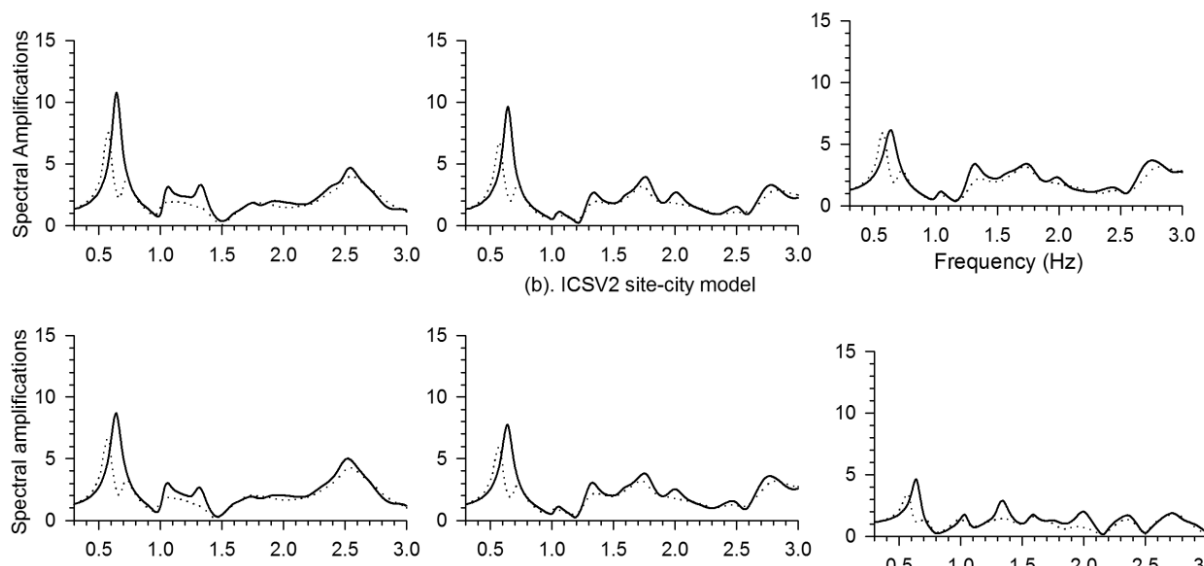

(c). ICSV3 site-city model
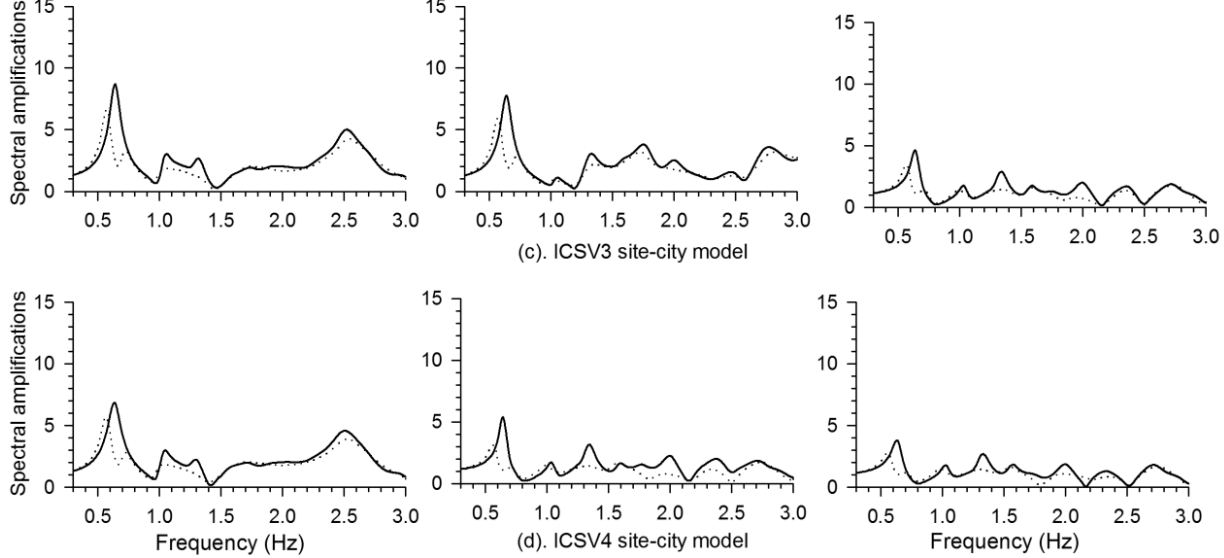

Fig. 9a-d. A comparison of spectral amplifications of free field motion at different locations in the absence and presence of city in the ICSV1-ICSV4 site-city models, respectively.

Minor increase of $S V F_{02 D}^{B}$ of basin with an increase of IC in the absence of city can be inferred (Zhu et al., 2019). However, the interaction of city with the basin has reduced the $S V F_{02 D}^{B}$ of basin to around $0.58 \mathrm{~Hz}$ in all the IC model. This reduction of $S V F_{02 D}^{B}$ of basin due to SCI was for the entire elliptical basin and was not limited to the area covered by the city. It was interesting to note that the fundamental frequency of buildings and the basin were matching, even after interaction. Table 5 depicts that SCI has caused a 
reduction of SAF at $S V F_{02 D}^{B}$ of basin of the order of $39.23 \%, 30.85 \%, 25.43 \%$ and $20.08 \%$ in the ICSV1-ICSV4 site-city models, respectively, at a distance of $36 \mathrm{~m}$. But, the obtained \% reduction of SAF at frequency $S V F_{02 D}^{S}$ as $79.83 \%, 75.99 \%, 70.49 \%$ and $66.67 \%$ in the ICSV1-ICSV4 site-city models, respectively, reveals that the \% reduction of SAF at $S V F_{02 D}^{S}$ is larger than that at $S V F_{02 D}^{S B}$. Table 5 also revealed an increase of $\%$ reduction of ASA in the free field motion with an increase of IC. The SCI effect on the free field motion was largest at the centre of city and decreasing towards the edge of city.

\section{Discussion and conclusions}

The analysis of simulated SH- and SV-wave responses of the various considered site-city models revealed that the obtained reduction of $F_{02 D}^{S B}$ of building, $F_{02 D}^{B}$ of basin, corresponding SAFs as well as splitting of bandwidth of fundamental mode of vibrations of both the basin and buildings corroborate with the findings in the past SCI studies (Guéguen and Bard, 2005; Kham et al., 2006; Semblat et al., 2008; Kumar and Narayan, 2018). The observed splitting of fundamental mode of vibrations of both the buildings and basin is due to an additional drop of SAF at $F_{02 D}^{S}$ of building on rock since the emanated seismic waves by the buildings at this frequency were out of phase to that of the incident S-wave (Jennings, 1970; Kanamori et al., 1991). The obtained larger \% reduction of $S H F_{02 D}^{B}$ of basin and corresponding SAF in the case of $\mathrm{SH}$-wave responses, even though the number of buildings were lesser, may be due to larger height of B16-building as compared to B12building used in the SV-wave simulations or due to buildings behaving as a shear beam for the SH-wave or may be due to both. The increase of $F_{02 D}^{B}$ of basin with an increase of IC in the absence of city corroborates with the finding of $Z$ hu et al. (2019). It was appealing to note that reduction of $F_{02 D}^{S B}$ of building and $F_{02 D}^{B}$ of basin due to SCI effects were unaffected by the increase of IC for both the polarizations of S-wave. The drastic increase of SCI effects on the responses of basin but only minor increase on response of building were obtained with an increase of IC for both the polarizations of S-wave. Although, the \% reduction of SAF at $S V F_{02 D}^{B}$ of basin was lesser than that at $S H F_{02 D}^{B}$, but, the role of IC in the SCI effects on the responses of buildings and basin was lager in the case of $\mathrm{SV}$-wave responses. 
Acknowledgements. The second and third authors of this paper are thankful to Indian Institute of Technology Roorkee, India for providing MHRD scholarship during M.Tech. Programme.

\section{References}

Bard P.-Y., Bouchon M., 1985: The two-dimensional resonance of sediment-filled valleys. Bull. Seismol. Soc. Am., 75, 2, 519-541.

Bard P.-Y., Chazelas J. L., Guéguen Ph., Kham M., Semblat J. F., 2005: Site-City Interaction. Chapter 5 of the book "Oliveira C. S., Roca A., Goula X. (Eds.): Assessing and Managing Earthquake Risk (Geo-Scientific and Engineering Knowledge for Earthquake Risk Mitigation: Developments, Tools and Techniques)", Springer (new book series on Geotechnical, Geological and Earthquake Engineering). Hardcover ISBN 1-4020-3524-1, 91-114.

Bard P.-Y., Chazelas J. L., Guéguen Ph., Kham M., Semblat J. F., 2008: Site-City Interaction. In: Oliveira C. S., Roca A., Goula X. (Eds.): Assessing and Managing Earthquake Risk. Springer, The Netherlands, 91-114, doi: 10.1007/978-1-4020-3608 $-8 \_5$.

Chávez-García F. J., Bard P.-Y., 1994: Site effects in Mexico City eight years after the September 1985 Michoacan earthquakes. Soil Dyn. Earthq. Eng., 13, 4, 229-247, doi : 10.1016/0267-7261(94)90028-0.

Emmerich H., Korn M., 1987: Incorporation of attenuation into time-domain computations of seismic wave fields. Geophysics, 52, 9, 1252-1264, doi : 10.1190/1.1442386.

Groby J.-P., Wirgin A., 2008: Seismic motion in urban site consisting of blocks in welded contact with a soft layer overlying a hard half-space. Geophys. J. Int., 172, 2, 725-758, doi: 10.1111/j.1365-246X.2007.03678.x.

Guéguen P., Bard P.-Y., Chávez-García F. J., 2002: Site-City Interaction in Mexico CityLike environments: An Analytical Study. Bull. Seismol. Soc. Am., 92, 2, 794-811, doi : 10.1785/0120000306.

Guéguen P., Bard P.-Y., 2005: Soil-structure and soil-structure-soil interaction: experimental evidence at the Volvi test site. J. Earthq. Eng., 9, 5, 657-693, doi : 10.1080 /13632460509350561.

Guéguen P., Colombi A., 2016: Experimental and numerical evidence of the clustering effect of structures on their response during an earthquake: A case study of three identical towers in the city of Grenoble, France. Bull. Seismol. Soc. Am., 106, 6, 2855-2864, doi : 10.1785/0120160057.

Guéguen P., Mercerat E. D., Singaucho J. C., Aubert C., Barros J. G., Bonilla L. F., Cripstyani M. P., Douste-Bacqué I., Langlaude P., Mercier S., Pacheco D. A., Pernoud M., Perrault M., Pondaven I., Wolyniec D., 2019: METACity-Quito: A SemiDense Urban Seismic Network Deployed to Analyze the Concept of Metamaterial for the Future Design of Seismic-Proof Cities. Seismol. Res. Lett., 90, 6, 2318-2326, doi : $10.1785 / 0220190044$. 
Merritt R. G., Housner G. W., 1954: Effect of foundation compliance on earthquake stresses in multi-story buildings. Bull. Seismol. Soc. Am., 44, 4, 551-569.

Israeli M., Orszag S. A., 1981: Approximation of radiation boundary conditions. J. Comput. Phys., 41, 1, 115-135, doi: 10.1016/0021-9991(81)90082-6.

IS 1893-1, 2002: Criteria for earthquake resistant design of structures - Part 1: General provision and buildings. Bureau of Indian Standards, https://law.resource.org /pub/in/bis/S03/is.1893.1.2002.pdf.

Jennings P. C., 1970: Distant motion from a building vibration test. Bull. Seismol. Soc. Am., 60, 6, 2037-2043.

Kanamori H., Mori J., Anderson D. L., Heaton T. H., 1991: Seismic excitation by the space shuttle Columbia. Nature, 349, 6312, 781-782, doi: 10.1038/349781a0.

Kham M., Semblat J.-F., Bard P.-Y., Dangla P., 2006: Seismic site-city interaction: main governing phenomena through simplified numerical models. Bull. Seismol. Soc. Am., 96, 5, 1934-1951, doi: 10.1785/0120050143.

Kristek J., Moczo P., 2003: Seismic wave propagation in viscoelastic media with material disconuties- a $3 \mathrm{D}$ 4th order staggered grid finite difference modeling. Bull. Seismol. Soc. Am., 93, 5, 2273-2280, doi : 10.1785/0120030023.

Kumar S., Narayan J. P., 2008: Absorbing boundary conditions in a fourth-order accurate SH-wave staggered grid finite difference algorithm. Acta Geophys., 56, 4, 10901108, doi : $10.2478 / \mathrm{s} 11600-008-0043-9$.

Kumar N., Narayan J. P., 2018: Quantification of site-city-interaction effects on the response of structure under double resonance condition. Geophys. J. Int., 212, 1, 422-441, doi: $10.1093 / \mathrm{gji} / \mathrm{ggx397.}$

Kumar N., Narayan J. P., 2019: Effects of site-city interaction and polarisation of the incident S-wave on the transfer function and fundamental frequency of structures. Nat. Hazards, 97, 2, 747-774, doi : 10.1007/s11069-019-03671-8.

Michel C., Guéguen P., 2018: Interpretation of the velocity measured in buildings by seismic interferometry based on Timoshenko beam theory under weak and moderate motion. Soil Dyn. Earthq. Eng., 104, 131-142, doi: 10.1016/j . soildyn.2017.09 .031.

Narayan J. P., 2005: Study of basin-edge effects on the ground motion characteristics using 2.5-D modeling. Pure Appl. Geophys., 162, 2, 273-289, doi : 10.1007/s00024-004 $-2600-8$.

Narayan J. P., Kumar V., 2013: A fourth-order accurate finite-difference program for the simulation of $\mathrm{SH}$-wave propagation in heterogeneous viscoelastic medium. Geofizika, 30, 2, 173-189.

Narayan J. P., Kumar V., 2014: Study of combined effects of sediment rheology and basement focusing in an unbounded viscoelastic medium using $P$ - $S V$-wave finitedifference modelling. Acta Geophys., 62, 6, 1214-1245, doi: 10.2478/s11600-013 -0199-9.

Sahar D., Narayan J. P., Kumar N., 2015: Study of role of basin shape in the sitecity interaction effects on the ground motion characteristics. Nat. Hazards, 75, 2, 1167-1186, doi : 10.1007/s11069-014-1366-2. 
Sahar D., Narayan J. P., 2016: Quantification of modification of ground motion due to urbanization in a 3D basin using viscoelastic finite difference modeling. Nat. Hazards, 81, 2, 779-806, doi: 10.1007/s11069-015-2105-z.

Schwan L., Boutin C., Padron L. A., Dietz M. S., Bard P.-Y., Taylor C., 2016: Sitecity interaction: theoretical, numerical and experimental crossed-analysis. Geophys. J. Int., 205, 2, 1006-1031, doi: 10.1093/gji/ggw049.

Semblat J.-F., Kham M., Bard P.-Y., 2008: Seismic-wave propagation in alluvial basins and influence of site-city interaction. Bull. Seismol. Soc. Am., 98, 6, 2665-2678, doi: $10.1785 / 0120080093$.

Stewart J. P., Seed R. B., Fenves G. L., 1999: Seismic soil-structure interaction in buildings. II: Empirical findings. J. Geotech. Geoenviron. Eng., 125, 1, 38-48, doi : 10.1061/(ASCE) 1090-0241(1999) 125:1(38).

Tsogka C., Wirgin A., 2003: Simulation of seismic response in an idealized city. Soil Dyn. Earthq. Eng., 23, 5, 391-402, doi: 10.1016/S0267-7261 (03)00017-4.

Wirgin A., Bard P.-Y., 1996: Effects of building on the duration and amplitude of ground motion in Mexico City. Bull. Seismol. Soc. Am., 86, 3, 914-920.

Wong H. L., Trifunac M. D., 1975: Two-dimensional anti-plane building-soil-building interaction for two or more buildings and for incident plane SH waves. Bull. Seismol. Soc. Am., 65, 6, 1863-1885.

Zeng C., Xia J., Miller R. D., Tsoflias G. P., 2012: An improved vacuum formulation for 2D finite-difference modeling of Rayleigh waves including surface topography and internal discontinuities. Geophysics, 77, 1, T1-T9, doi: 10.1190/geo2011-0067.1.

Zhu C., Thambiratnam D., Gallage C., 2019: Inherent characteristics of 2D alluvial formations subjected to in-plane motion. J. Earthq. Eng., 23, 9, 1512-1530, doi : 10.1080 /13632469.2017.1387199. 